\title{
Apo E phenotype and changes in serum lipids in adult patients during growth hormone replacement
}

\author{
G P Leese $^{1}$, M Wallymahmed ${ }^{2}$, G Wieringa ${ }^{4}$, C VanHeyningen ${ }^{3}$ and I A MacFarlane ${ }^{2}$ \\ ${ }^{1}$ Department of Endocrinology, Ninewells Hospital, Dundee, UK, Departments of ${ }^{2}$ Endocrinology and ${ }^{3}$ Biochemistry, Aintree Hospitals, Liverpool, UK and \\ ${ }^{4}$ Department of Biochemistry, Christies Hospital NHS Trust, Manchester, UK \\ (Correspondence should be addressed to G Leese, Ward 1 and 2, Ninewells Hospital, Dundee DD1 9SY, UK)
}

\begin{abstract}
Objective: To determine whether apo E phenotype influences changes in lipid profiles induced by growth hormone replacement in growth hormone $(\mathrm{GH})$-deficient adults.

Designs: Patients were treated for 6 months with recombinant human $\mathrm{GH}(\mathrm{hGH})$, given in a dose of $0.125 \mathrm{U} / \mathrm{kg}$ per week for 4 weeks followed by $0.25 \mathrm{U} / \mathrm{kg}$ per week thereafter. The effects on serum lipids and the influence of apo E phenotype were examined.

Methods: Thirty patients (aged 35.1 \pm 11.8 years; mean \pm s.D.) with adult growth hormone deficiency with included in the study. Fasting serum samples were analysed for apo E phenotype total cholesterol, high-density lipoprotein (HDL)-cholesterol, triglycerides, lipoprotein (a) (Lp(a)) and IGF-I. Low-density lipoprotein (LDL)-cholesterol was calculated using the Friedwald formula.

Results: Six months of replacement treatment with hGH resulted in a reduction in HDL-cholesterol from $0.90 \pm 0.10$ to $0.68 \pm 0.08 \mathrm{mmol} / \mathrm{l}(P<0.01)$, and a small, non-significant reduction in total cholesterol from $6.14 \pm 0.40$ to $5.99 \pm 0.35 \mathrm{mmol} / \mathrm{l}(P=0.06)$. There was no significant change in the other lipid parameters. The decrease in HDL-cholesterol concentration was greater in patients carrying the apo E2 allele $(0.40 \pm 0.07 \mathrm{mmol} / \mathrm{l}, P<0.05)$ than in patients homozygous for the apo E3 allele $(0.23 \pm 0.04 \mathrm{mmol} / \mathrm{l})$ and patients carrying the apo $\mathrm{E} 4$ allele $(0.15 \pm 0.36 \mathrm{mmol} / \mathrm{l})$. Patients with the apo E4 allele had lower baseline cholesterol concentrations than patients lacking the apo E4 allele, and this persisted after treatment with hGH $(P<0.05)$.

Conclusions: Apo E phenotype may be a determining factor in the response of HDL-cholesterol to hGH in GH-deficient adults.
\end{abstract}

European Journal of Endocrinology 140 174-179

\section{Introduction}

Patients with panhypopituitarism have adverse lipid profiles and these are believed to contribute to cardiovascular morbidity (1-3). Treatment of growth hormone (GH)-deficient adults with recombinant human $\mathrm{GH}(\mathrm{hGH})$ has been reported to decrease total cholesterol by $4-15 \%(1,3-7)$. Changes in serum lowdensity lipoprotein (LDL)-cholesterol, triglycerides and high-density lipoprotein (HDL)-cholesterol concentrations have also been noted. Some studies show an increase in HDL-cholesterol after hGH $(3,6)$, although others have shown either no change $(1,7,8)$ or a reduction in HDL-cholesterol and related apolipoproteins $(9-11)$. Our previous report of reductions in HDLcholesterol after $\mathrm{GH}$ replacement is at variance with other studies $(12,13)$, and it is important to understand why our population may be different.

It is unclear why the hyperlipidaemia in some patients responds more favourably to hGH replacement than does that in others. Apolipoprotein E is important in the clearance of remnant intermediate-density lipoprotein (IDL) particles, very-low-density lipoproteins
(VLDL) and LDL (14). There are a number of polymorphisms of the apo E gene, with the apo E3 genotype being most common. In the presence of excess triglyceride production, for example in diabetes, the apo E2 genotype is associated with a further exacerbation of hyperlipidaemia as a result of lack of peripheral clearance of remnant particles. As GH can affect hepatic triglyceride production, we set out to determine whether apo E phenotype contributed to changes in plasma lipid profiles induced by hGH replacement in GH-deficient adults.

\section{Patients and methods}

We recruited adult hypopituitary patients whose condition had been stabilised on pituitary hormone replacement for at least 6 months and who had been GH deficient for at least 24 months. GH deficiency was defined as a peak $\mathrm{GH}$ concentration of less than $10 \mathrm{mU} / \mathrm{l}$ after stimulation with either insulin or glucagon. Patients were excluded if they had any of the following: evidence of ischaemic heart disease, chronic liver or 
Table 1 Causes of pituitary insufficiency and replacement therapy provided for patients with $\mathrm{GH}$ deficiency $(n=30)$.

\begin{tabular}{lllr}
\hline Aetiology of GH deficiency & No. & Replacement therapy & No. \\
\hline Chromophobe adenoma & 9 & Isolated GH & 7 \\
Craniopharyngioma & 8 & Corticosteroids & 19 \\
Prolactinoma & 6 & Thyroxine & 16 \\
Hypothalamic glioma & 2 & Sex steroids & 20 \\
Optic nerve glioma & 1 & Desmopressin & 8 \\
Ectopic pituitary tumour & 1 & & \\
Midbrain glioma & 1 & & \\
Parietal glioblastoma & 1 & & \\
Suprasellar meningioma & 1 & & \\
\hline
\end{tabular}

renal disease, diabetes mellitus, pregnancy, history of malignancy, treatment with GH during the previous 12 months and known hypersensitivity to $m$-cresol. Causes of the GH deficiency and treatment given are shown in Table 1 . The study was approved by the Aintree Hospital ethics committee and all patients gave written informed consent to participate in the study. Further details of the patient group have been published previously (15).

All patients received hGH for 6 months (hGH; Genotropin, Pharmacia Ltd, Milton Keynes, UK). For the first 4 weeks, the hGH dose was $0.125 \mathrm{U} / \mathrm{kg}$ per week, then it was increased to $0.25 \mathrm{U} / \mathrm{kg}$ per week for the following 5 months. The weekly dose was given as seven equal daily subcutaneous injections given at bedtime. The maximum daily dose was $4 \mathrm{U}$ per day, and doses were reduced if side effects occurred.

Thirty-two patients (aged 35.1 \pm 2.0 years, mean \pm S.E., range 20-59 years) started the study, but two patients withdrew from the study because of side effects of oedema and arthralgia. Patient characteristics have been described in detail elsewhere $(11,15)$.

Patients were assessed for weight, height, and blood pressure every 3 months. Changes in concomitant medication were recorded. At baseline and 6 months, fasting blood samples were collected and serum separated for subsequent analysis of total cholesterol, triglycerides (Bayer reagents for enzymatic assays on a DAX autoanalyser), HDL-cholesterol (by phosphotungstic acid $\mathrm{MgCl}_{2}$ method), and serum lipoprotein (a) (Lp(a)) (Pharmacia radioimmunoassay). Serum samples were stored at $-80{ }^{\circ} \mathrm{C}$ and analyses were performed in one batch. LDL-cholesterol concentrations were calculated using the Friedwald formula (16). At the 6-month visit, blood was collected for analysis of apo E phenotype, which was determined by a previously described method (17) that had been modified to include immunoblotting and detection of apo $\mathrm{E}$ phenotypes with a combination of antibody probes (18).

\section{Statistics}

Data are expressed as means \pm S.E. unless otherwise stated. Groups of data were compared using one-way analysis of variance (ANOVA), and individual biochemical analytes were compared using paired $t$-tests for intragroup variations and standard $t$-tests for intergroup variations. The serum $\operatorname{Lp}(\mathrm{a})$ data underwent log transformation for statistical comparison. A Spearman's ranked correlation coefficient was used to assess for correlation ( $\rho$ is the correlation coefficient). Significance was assumed with a $P$ value $<0.05$.

\section{Results}

Ten male and 20 female patients were recruited. Mean age was $35.1 \pm 2.2$ years, weight $83.7 \pm 4.3 \mathrm{~kg}$, estimated duration of GH deficiency $5.6 \pm 0.6$ years, peak stimulated $\mathrm{GH}$ response $3.1 \pm 0.5 \mathrm{mU} / \mathrm{l}$ and baseline insulin-like growth factor-I (IGF-I) $11.9 \pm$ $1.3 \mathrm{nmol} / \mathrm{l}$. The number of patients with each apo $\mathrm{E}$ phenotype is shown in Table 2. In our GH-deficient patients, 6 months of treatment with hGH resulted in a reduction in HDL-cholesterol from $0.90 \pm 0.10 \mathrm{mmol} / \mathrm{l}$ to $0.68 \pm 0.08 \mathrm{mmol} / \mathrm{l}$ (Table $2 ; P<0.05$ ) and a small but statistically non-significant reduction in total cholesterol $(P=0.06)$ (Table 3$)$. There were no significant changes in serum LDL-cholesterol, triglyceride or serum Lp(a) concentrations.

Serum HDL-cholesterol concentrations showed a significant decrease after hGH treatment in patients with the apo E2 allele and patients homozygous for apo E3 (Table 4). Although no significant changes were seen in patients with the apo $\mathrm{E} 4$ allele, patient numbers in this group were small $(n=5)$. Baseline serum HDLcholesterol concentrations were significantly greater in

Table 2 Apo E phenotypes of the 30 patients.

\begin{tabular}{lcl}
\hline Apo E phenotype & No. & Sex \\
\hline Apo E2/E2 & 1 \\
Apo E2/E3 & 9 & \\
Apo E3/E3 & 15 & $2 M: 8 F$ \\
Apo E3/E4 & 3 \\
Apo E2/E4 & $2\}$ & $5 \mathrm{M}: 10 \mathrm{~F}$ \\
\hline
\end{tabular}


Table 3 Effects of 6 months of GH treatment on serum lipid profiles and IGF-I concentrations (means \pm S.E.).

\begin{tabular}{lccr}
\hline Lipid parameter & Baseline & After treatment & \multicolumn{1}{c}{$\boldsymbol{P}$} \\
\hline Total cholesterol $(\mathrm{mmol} / \mathrm{l})$ & $6.14 \pm 0.40$ & $5.99 \pm 0.35$ & 0.06 \\
HDL-cholesterol $(\mathrm{mmol} / \mathrm{l})$ & $0.90 \pm 0.10$ & $0.68 \pm 0.08$ & $<0.01$ \\
Triglycerides $(\mathrm{mmol} / \mathrm{l})$ & $2.16 \pm 0.31$ & $2.34 \pm 0.32$ & 0.71 \\
LDL-cholesterol $(\mathrm{mmol} / \mathrm{l})$ & $4.27 \pm 0.38$ & $4.22 \pm 0.32$ & 0.31 \\
Lp(a) $(\mathrm{mg} / \mathrm{l})$ & $322.7 \pm 128.6$ & $286.9 \pm 103.3$ & 0.34 \\
IGF-l (mmol/l) & $11.9 \pm 1.3$ & $38.2 \pm 3.1$ & $<0.0001$ \\
\hline
\end{tabular}

patients with the apo E2 allele than in those with the apo E3 allele at baseline, but after 6 months of treatment with hGH this difference no longer existed (Table 4). The decrease in HDL-cholesterol was $0.40 \pm 0.07 \mathrm{mmol} / \mathrm{l}$ in patients with the apo E2 allele, whereas the decrease was $0.23 \pm 0.04 \mathrm{mmol} / \mathrm{l}$ in patients homozygous for apo E3 $(P<0.05)$ and $0.15 \pm 0.36 \mathrm{mmol} / \mathrm{l}$ in patients with the apo $\mathrm{E} 4$ allele There was no correlation between IGF-I and changes in HDL-cholesterol concentration ( $\rho=0.2$, not significant).

Serum LDL-cholesterol concentrations were significantly lower in patients with the apo E4 allele than in patients lacking the apo E4 allele (Table 4), both at baseline $(P<0.05)$ and after 6 months of treatment with hGH $(P<0.01)$. There were, however, no significant changes in LDL-cholesterol concentration after hGH in any of the apo E polymorphic patient subgroups, and there was no significant difference in change in LDL-cholesterol between the groups. The mean change in LDL-cholesterol was $+0.02 \pm 0.30 \mathrm{mmol} / \mathrm{l}$ for the apo E2 group, $-0.36 \pm 0.25 \mathrm{mmol} / \mathrm{l}$ for the apo E3 group and $0.00 \pm 0.32 \mathrm{mmol} / \mathrm{l}$ for the apo $\mathrm{E} 4$ group. As a result of the differences in LDL-cholesterol, there was a trend towards lower total cholesterol concentrations in the patient group with the apo E4 allele (Table 4), although this did not achieve statistical significance $(P=0.07$ after 6 months hGH).

There were no significant differences in triglyceride, total cholesterol or $\mathrm{Lp}(\mathrm{a})$ concentrations between patients with different apo E polymorphisms. Apo E phenotype subgroups were not associated with changes in serum concentrations during hGH with respect to total cholesterol (apo E2 -0.22 \pm 0.40 , apo E3 $-0.59 \pm 0.32$, apo E4 $-0.23 \pm 0.34 \mathrm{mmol} / \mathrm{l})$, triglycerides (apo E2 +0.36 \pm 0.31 , apo $\mathrm{E} 3+0.01 \pm 0.38$, apo E4 $-0.17 \pm 0.28 \mathrm{mmol} / \mathrm{l}$ ), or serum $\mathrm{Lp}$ (a) (apo E2 $-152 \pm 101$, apo E3 $-130 \pm 99$, apo E4 $-29 \pm$ $23 \mathrm{mg} / \mathrm{l})$ (ANOVA, not significant).

\section{Discussion}

In our series of studies of 30 patients treated with hGH, we have previously reported a small but non-significant decrease in total cholesterol, a significant decrease in

Table 4 Lipid parameters at baseline and after 6 months of treatment with hGH, according to apo E alleles (means \pm S.E.)

\begin{tabular}{|c|c|c|c|}
\hline & $\begin{array}{l}\text { Apo E2 } \\
(n=10)\end{array}$ & $\begin{array}{l}\text { Apo E3 } \\
(n=15)\end{array}$ & $\begin{array}{l}\text { Apo E4 } \\
(n=5)\end{array}$ \\
\hline \multicolumn{4}{|c|}{ Total cholesterol (mmol/l) } \\
\hline 0 month & $6.65 \pm 0.39$ & $6.36 \pm 0.37$ & $5.42 \pm 0.73$ \\
\hline 6 months & $6.44 \pm 0.38$ & $5.77 \pm 0.28$ & $5.19 \pm 0.50$ \\
\hline \multicolumn{4}{|c|}{ HDL-cholesterol (mmol/l) } \\
\hline 0 month & $1.05 \pm 0.06$ & $0.84 \pm 0.05 \dagger$ & $1.06 \pm 0.20$ \\
\hline 6 months & $0.65 \pm 0.07 \ddagger$ & $0.61 \pm 0.06 \ddagger$ & $0.91 \pm 0.19$ \\
\hline \multicolumn{4}{|c|}{ LDL-cholesterol (mmol/l) } \\
\hline 0 month $^{*}$ & $4.85 \pm 0.40$ & $4.54 \pm 0.29$ & $3.15 \pm 0.53$ \\
\hline 6 months ${ }^{* *}$ & $4.86 \pm 0.25$ & $4.18 \pm 0.23$ & $3.15 \pm 0.42$ \\
\hline \multicolumn{4}{|c|}{ Triglycerides (mmol/l/) } \\
\hline 0 month & $1.67 \pm 0.16$ & $2.15 \pm 0.37$ & $2.66 \pm 0.73$ \\
\hline 6 months & $2.03 \pm 0.45$ & $2.16 \pm 0.23$ & $2.49 \pm 0.57$ \\
\hline \multicolumn{4}{|l|}{ Lp(a) (mg/l) } \\
\hline 0 month & $376.2 \pm 165.7$ & $390.9 \pm 170.6$ & $209.6 \pm 119.8$ \\
\hline 6 months & $224.2 \pm 90.8$ & $261.2 \pm 91.9$ & $185.8 \pm 97.0$ \\
\hline
\end{tabular}

ANOVA comparison between three groups: ${ }^{*} P<0.05,{ }^{*} P<0.01 . t$-tests showed that the apo E4 group had a significantly lower LDL-cholesterol at $0(P<0.05)$ and 6 months $(P<0.01)$. $t$-test comparing apo E2 and apo E3 groups: $\dagger P<0.05$; paired $t$-test for intragroup 0 and 6 month comparison: $\ddagger P<0.05$. 
HDL-cholesterol and no significant change in LDLcholesterol or triglycerides (11). Previous studies in adults have demonstrated either no change in HDLcholesterol $(1,7,8,13,19,20)$ or even a small increase after prolonged treatment $(3,6)$. Although the large Australian study (13) showed no overall change in HDL-cholesterol, interestingly, there were significant differences in changes in HDL-cholesterol concentration after hGH between different centres. These differences in response of HDL-cholesterol to hGH remain unexplained. The present study was performed to examine reasons for this difference in results.

There are three common apo E alleles in the general population. The frequency of apo E2, apo E3 and apo E4 varies between different populations (21). The frequency of apo E2 allele in our population (33\%) was much greater than those reported in previous studies: $4 \%(22)(P<0.01)$ and $14 \%(23)(P<0.05$; chi-squared analysis). One in three of our patients carried the apo E2 allele, which is a much higher prevalence than would normally be expected (21). We have demonstrated that the lipid profiles of patients with the apo E2 allele respond least well to hGH replacement, in that their LDL-cholesterol did not decrease at all, the HDL-cholesterol decreased by the greatest degree, and their triglycerides increased. Patients homozygous for the apo E3 allele responded in a more favourable and classical way than has previously been reported in the literature $(1,3,6,7)$. Thus our high proportion of patients with the apo E2 allele may explain the overall difference in results compared with previous studies.

Apo $\mathrm{E}$ is believed to promote both the conversion of triglyceride-rich VLDL to LDL and the clearance of VLDL from the circulation via the apo $\mathrm{E}$ remnant receptor. These effects, however, may be diminished in the presence of the apo E2 allele (21). Presence of the apo E2 phenotype is usually associated with a slightly lower LDL-cholesterol concentration $(24,25)$, probably because of impaired conversion of VLDL- to LDLcholesterol. However, in conditions in which there is increased hepatic triglyceride and VLDL output, the apo E2 phenotype is associated with mixed hyperlipidaemia as a result of impaired peripheral clearance. GH is believed to increase hepatic VLDL secretion (26) and to increase the number of LDL receptors (27), hence potentially promoting an increased clearance of VLDL/ LDL from the circulation. Failure to decrease LDL concentrations in our E2 group suggests that the effects of GH are compromised in the presence of the apo E2 allele. Thus, although there may be an increase in hepatic VLDL secretion (seen as an increase in triglycerides) leading subsequently to increased LDL production, a balance is reached between increased LDL production and increased clearance, such that no overall change occurs in circulating LDL concentrations. Further labelled substrate studies that determine the VLDL and LDL clearance pathways are warranted to confirm any such increased flux during hGH therapy.

Patients homozygous for E3 have unimpaired VLDL conversion to LDL and normal LDL clearance. Interestingly, in our homozygous E3 group there was no increase in circulating triglyceride concentrations during the study but a decrease in LDL concentrations, which would be predicted because hGH can have its full effect on promoting LDL clearance. This indicates that, in the absence of apo E2, hGH can increase the rate of flux sufficiently to clear LDL and prevent any increase in triglycerides.

One previous study examined the impact of apo E phenotype on lipid response to hGH (28). Although the investigators demonstrated an overall increase in HDL-cholesterol concentration, this increase was less marked in patients with the apo E2 allele (E3/2 - 2.5\%) than in patients homozygous for the apo E3 allele (E3/3 $-12.2 \%$ ), again indicating a possible difference in response between different apo E genotypes.

We have demonstrated an overall significant decrease in HDL-cholesterol concentrations during the study period. This is difficult to explain fully. To date, there is no evidence for a direct role of GH on HDL-cholesterol metabolism, and previous reports have noted increases $(3,6)$, decreases $(9-11)$ and no change $(1,7)$ during hGH treatment. White et al. (29) observed an even greater decrease in HDL-cholesterol (33\%) during hGH therapy, albeit in children in whom the decrease correlated inversely with an increase in triglyceride concentrations. The decreases in our study were most pronounced in the apo E2 group, in whom an increase in triglycerides also occurred, but was not significant in the E4 group, in whom triglycerides decreased. In otherwise healthy people, the greatest increases in HDLcholesterol concentration and the smallest increase in plasma cholesterol ester transfer protein (CETP) activity after feeding are associated with individuals carrying the apo E4 phenotype (30), compared with other apo E phenotypes. If this is also the case in GH-deficient adults, then hGH replacement may be expected to be most beneficial in patients with the apo E4 phenotype. The blunted CETP activity in apo E4 individuals may promote HDL clearance of cholesterol; CETP activity is recognised to be inversely related to HDL-cholesterol concentrations (31). Thus the association between low CETP activity and the apo E4 phenotype may result in increased reverse cholesterol transport and explain not only why HDL-cholesterol did not decrease significantly in the apo E4 group, but also the low LDL-cholesterol concentration both at baseline and after treatment with hGH, as seen in our study. Further studies (with larger numbers of patients) that include concomitant evaluation of parameters such as LDL receptors, CETP and lipase activity are warranted. This will allow further advance in our understanding of the role of apo E polymorphism in the lipid response to GH therapy. 
Interestingly, apo $\mathrm{E}$ phenotype was unrelated to serum $\mathrm{Lp}(\mathrm{a})$ concentration in our cohort of patients, unlike the findings of previous studies (32), and apo E phenotype did not predict the response of $\mathrm{Lp}(\mathrm{a})$ to hGH. However serum Lp(a) concentrations have a large physiological variability (33), which can make it difficult to identify any pharmacological effect.

In our study, there was a preponderance of female patients $(67 \%)$, which may have contributed to the unusual HDL-cholesterol response to hGH. In the Australian study (13), there was a variety of responses of HDL-cholesterol to hGH between centres, but it is unclear what the patient sex ratio was in each of the centres. Twenty of the patients were receiving sex steroids and the other 10 were eugonadal. Treatment with sex hormones did not alter throughout the study period and these are therefore unlikely to be responsible for changes in lipid profiles.

Patients with GH deficiency are a hetereogenous group who, in terms of their serum lipids, may respond in diverse ways, depending on a variety of genetic factors, including apo E phenotype. Patients' lipid profiles should be carefully monitored after they start hGH treatment, especially if they are at high risk of ischaemic heart disease.

\section{Acknowledgements}

We would like to thank Pharmacia pharmaceuticals for their support of this study.

\section{References}

1 Cuneo RC, Salomon F, Watts GF, Hesp R \& Sonsken PH. Growth hormone treatment improves serum lipids and lipoproteins in adults with growth hormone deficiency. Metabolism 199342 1519-1523.

2 deBoer H, Blok GJ, Voerman HJ, Philips M \& Schouten JA. Serum lipids in growth hormone deficient men. Metabolism 199443 199-203.

3 Beshayh SA, Henderson A, Niththyananthan R, Skinner E, Anyaoku V, Richmond W et al. The effects of short and long term growth hormone replacement therapy in hypopituitary adults on lipid metabolism and carbohydrate tolerance. Journal of Clinical Endocrinology and Metabolism 199580 356-363.

4 Binnerts A, Roel Stewart G, Paul Wilson JH, Hoogerbrugge N, Pols HAP, Birkenhager JC et al. The effects of growth hormone administration in growth hormone deficient adults on bone protein, carbohydrate and lipid homeostasis, as well as on body composition. Clinical Endocrinology 199237 79-87.

5 Salomon F, Cuneo RC, Hesp R \& Sonksen PH. The effects of treatment with recombinant human growth hormone on body composition and metabolism in adults with growth hormone deficiency. New England Journal of Medicine 1989321 17971803.

6 Eden S, Wiklund O, Oscarsson J, Rosen T \& Bengtsson B-A. Growth hormone treatment of growth hormone deficient adults results in a marked increase in $L p(a)$ and HDL-cholestero concentrtaions. Arteriolsclerosis Thrombosis 199313 296-301.

7 Russell-Jones DL, Watts GF, Weissberger A, Naoumova R, Myers J, Thompson GR et al. The effect of growth hormone replacement on serum lipids, lipoproteins, apolipoproteins and cholestero precursors in adult growth hormone deficient patients. Clinical Endocrinology 199441 345-350.

8 Garry P, Collins P \& Devlin JG. An open 36-month study of lipid changes with growth hormone in adults: lipid changes following replacement of growth hormone in adult acquired growth hormone deficiency. European Journal of Endocrinology 1996134 61-66.

9 Asayama K, Amemiya S, Kusano S \& Kato K. Growth hormone induced changes in postheparin plasma lipoprotein lipase and hepatic triglyceride lipase activities. Metabolism 198433 129131.

10 Blackett PR, Weech PK, McConathy WJ \& Fesmire JD. Growth hormone in the regulation of hyperlipidaemia. Metabolism 1982 31 117-120.

11 Leese GP, Wallymahmed M, Van Heyningen C, Tames F \& MacFarlane IA. HDL-cholesterol reductions associated with adult growth hormone. Clinical Endocrinology 199849 673-678.

12 Attanasio AF, Lamberts SWJ, Matranga AMC, Birkett MA, Bates PC, Valk NK et al. Adult growth hormone deficient patients demonstrate heterogeneity between childhood onset and adult onset before and during growth hormone treatment. Journal of Clinical Endocrinology and Metabolism 199782 82-88.

13 Cuneo RC, Judd S, Wallace JD, Perry-Keene D, Burger H, Lim-Tio S et al. The Australian multicenter trial of growth hormone $(\mathrm{GH})$ treatment in GH-deficient adults. Journal of Clinical Endocrinology and Metabolism 199883 107-116.

14 Schaefer EJ, Gregg RE, Ghiselli G, Forte TM, Ordovas JM, Zech LA et al. Familial apolipoprotein $\mathrm{E}$ deficiency. Journal of Clinical Investigation 198678 1206-1219.

15 Wallymahmed ME, Foy P, Shaw D, Hutcheon R, Edwards RHT \& MacFarlane IA. Quality of life, body composition and muscle strength in adult growth hormone deficiency: the influence of growth hormone replacement therapy for up to 3 years. Clinical Endocrinology $199747439-446$.

16 Friedwald WT, Levy RL \& Fredrickson DS. Estimation of the concentration of low density lipoprotein cholesterol in plasma without the use of the preparative ultracentrifuge. Clinical Chemistry $197218499-502$.

17 Kane JW \& Gowland E. A method for the identification of apolipoprotein E isoforms employing chemical precipitation and flat bed isoelectric focusing in agarose. Annals of Clinical Biochemistry 198625 509-513.

18 McDowell IFW, Brian Wisdom G \& Trimble ER. Apolipoprotein E phenotype determined by agarose gel electrofocusing and immunoblotting. Clinical Chemistry 198825 638-644.

19 Oscarsson J, Ottosson M, Wiklund O, Marin P, Vikman-Adolfsson, Bjorntorp P et al. Low dose continuously infused growth hormone results in increased lipoprotein (a) and decreased low density lipoprotein cholesterol concentrations in middle aged men. Clinical Endocrinology 199441 109-116.

20 O'Halloran DJO, Wieringa G, Tsatsoulis A \& Shalet S. Increased serum lipoprotein (a) concentrations after growth hormone treatment in patients with isolated growth hormone deficiency. Annals of Clinical Biochemistry 199633 330-334.

21 Davignon J, Gregg RE \& Sing CF. Apolipoprotein E polymorphism and atherosclerosis. Arteriosclerosis Thrombosis 19888 1-21.

22 Manttari M, Koskinen P, Ehnholm C, Huttunen \& Manninen V. Apolipoprotein E polymorphism influences the serum cholesterol response to dietary intervention. Metabolism 199140 217-221.

23 Zambon D, Ros E, Casals E, Sanllehy C, Bertomeu A \& Campero I. Effect of lipoprotein E polymorphism on the serum lipid response to a hypolipidaemic diet rich in monounsaturated fatty acids in patients with hypercholesterolemia and combined hyperlipidemia. American Journal of Clinical Nutrition 199561 141-148.

24 Kamboh MI, Aston CE, Ferrell RE \& Hamman RF. Impact of apolipoprotein $\mathrm{E}$ polymorphism in determining interindividual variation in total cholesterol and low density lipoprotein cholesterol in Hispanics and non-Hispanic whites. Atherosclerosis 199398 201-211.

25 Xhignesse M, Lussier-Cacan S, Sing CF, Kessling AM \& Davignon J. Influences of common variants of apolipoprotein E on measures of 
lipid metabolism in a sample selected for health. Arteriosclerosis Thrombosis 199111 1100-1110.

26 Elan MB, Simkevich CP, Solomon SS, Wilcox HG \& Heinberg M. Stimulation of in vitro triglyceride synthesis in the rat hepatocyte by growth hormone treatment in vivo. Endocrinology 1988122 1397-1402.

27 Rudling M, Norstedt G, Olivecrona H, Reihner E, Gustafsson J-A \& Angelin B. Importance of growth hormone for the induction of hepatic low density lipoprotein receptors. Proceedings of the National Academy of Sciences of the USA 199289 6983-6987.

28 Johannsson G, Oscarsson J, Rosen T, Wiklund O, Olssen G, Wilhelmsen L et al. Effect of 1 year growth hormone therapy on serum lipoprotein (a) levels in growth hormone deficient adults. Influence of gender and apo(a) and apo E phenotype. Arteriosclerosis, Thrombosis and Vascular Biology 199515 2142-2150.

29 White RM, Schaefer EJ \& Papodopoulos NM. The effect of growth hormone administration on lipids and lipoproteins in growth hormone deficient patients. Proceedings of the Society for Experimental Biology and Medicine 1983173 63-67.
30 Martin LJ, Connelly PW, Nancoo D, Wood N, Zhang ZJ, Maguire G et al. Cholesterol ester transfer protein and high density lipoprotein responses to cholesterol feeding in men: relationship to apolipoprotein E genotype. Journal of Lipid Research 199334 437-446.

31 Tall AR. Plasma cholesterol ester transfer protein. Journal of Lipid Research 199334 1255-1274.

32 deKnijff P, Kaptein A \& Boomsma D. Apolipoprotein E polymorphism affects plasma levels of lipoprotein (a). Atherosclerosis 1991 90 169-174.

33 Mackness MI, Bhatnagar D, Wieringa G, Tsatsoulis A \& Shalet S. A comparative study of six commercial lipoprotein (a) assays in seventeen laboratories within the British Isles. Annals of Clinical Biochemistry 199633 63-70.

Received 14 October 1998

Accepted 14 October 1998 